\title{
Introducing the concepts and methods of humanism into education for ensuring quality sustainable development
}

\author{
Mykola Popovych ${ }^{1 *}$, Vasyl Levkulych ${ }^{2}$, Yuriy Khodanych ${ }^{3}$, Tereziia Popovych $^{4}$ \\ ${ }^{1}$ Doctor of Sciences (in Social Philosophy), Professor, Professor of Department of Theoretical-Law \\ and Social-Humanitarian Disciplines, State Agrarian and Engineering University in Podilya, \\ Kamianets-Podilskyi, Ukraine \\ ${ }^{2}$ Candidate of Philosophical Sciences, Associate Professor, Head of Department of Philosophy, \\ Uzhhorod National University, Uzhhorod, Ukraine \\ ${ }^{3}$ Candidate of Philosophical Sciences, Associate Professor at the Department of Philosophy, \\ Uzhhorod National University, Uzhhorod, Ukraine \\ ${ }^{4}$ Candidate of Law, Associate Professor, Associate Professor of the Department of Theory and \\ History of State and Law, Uzhhorod National University, Uzhhorod, Ukraine
}

\begin{abstract}
Humanism as a principle for sustainable development of society, a model for the management of education and public education, is recognized as a fundamental principle by proponents of various schools of thought, social science, management and philosophy, and pedagogy. In their view, the philosophy of education and upbringing should clearly delineate the range of humanistic and moral values, define the social institutions designed to form an orientation towards these values, justify the relationship between the individual and the social qualities of the individual that could contribute to the "spirit of democracy" in society. However, addressing these important issues requires an exploration of morality - identifying its nature, its functions in cognizing the world, and how it differs from other forms of cognition. According to the proponents of this socially-oriented direction of the management and educational philosophy, an important aim of education and upbringing is to develop the individual's ability to reflect on moral topics; and this, they argue, is achieved mainly through the "language of morality" logic.
\end{abstract}

\section{Introduction}

Morality, according to Plato, is considered as one of the eternal ideas or forms of cognition existing in the supersensible world. The task of cognition in the realm of morality, in the view of Plato, is to discover for oneself the idea of the good. It can be comprehended through intuition in a moment when it is separated from the object. And by comprehending the essence of the idea of the good, it is possible to find justification for our thoughts about the good already in the process of learning. Therefore, according to Plato, our need to know the idea of the good, beauty etc. should be justified in the process of education and upbringing. The meaning of the idea of the good is manifested in the logic of our thinking, in our language, which does not refer only to the world of things. The only condition under which language has meaning is, according to Plato, the existence of a supersensible world described by means of language, i.e., the world of pure ideas, including the idea of the good which is analogous to the world of phenomena. In other words, Plato believes that the process of moral education has the aim of discovering moral ideas,

* Corresponding author:professordfn@gmail.com 
revealing their content, in modern language, through their linguistic function. Language reveals the criterion of the correctness of our thoughts. These Plato's provisions are widely used by modern philosophers when they formulate the purpose, forms and methods of management of education and ethical upbringing.

\section{Research methodology}

Those scientific directions that orient management, education and upbringing towards the affirmation of justice, equality, freedom should incorporate the philosophical-ethical and sociological aspects of these concepts, which are only possible in pedagogy provided they are supported by the philosophy of education and the management of education. Some specialists have noted the particular importance of philosophical analysis of concepts related to the process of education and upbringing, arguing that this would deepen and broaden the general concept of values, thus enriching axiological theory in general [1]. "Immediate moral education centers around the knowledge of the 'language of morality', and it is the task of philosophers to help the individual to understand the role of language in moral considerations", writes A. Harris [2]. R. Barrow, for instance, considers it an important task of educational philosophy to engage people, especially young people, in logical, rational thinking, to teach them the techniques of thinking, to promote, in his opinion, a deeper understanding of the world [3].

\section{Results of the research}

The main focus of the proponents of this conception in the philosophy of education and upbringing is to justify the purpose of educational and moral and upbringing development, its methods and means. Hence, the concept of philosophy of education and upbringing, ethics, social and pedagogical management, which in the Western philosophy of education is called "new humanism", unites representatives of philosophy and ethics, pedagogy and linguistic analysis, social management, psychologists of Jean Piaget's school and his contemporary followers, a number of sociologists, etc. In contrast to, for example, the philosophy of pragmatism education, representatives of "new humanism" (P. Hirst, D. Wilson, R. Peters, M. Warnock, L. Kohlberg, A. Harris and others) link the process of upbringing and education with the value orientation of people [4]. Applying the methodological guidelines of the philosophy of linguistic analysis to the problems of education and upbringing, proponents of the "new humanism" often combine them with the ideas of Plato, Kant and other major educational and ethical thinkers of previous eras. This is particularly evident in the treatment of morality and its language, and their significance for the process of education and upbringing.

The influence of Platonism appears to be most clearly reflected in the system of education, training and upbringing developed by P. Hirst. Like Plato, Hirst recognizes the existence of ideas or forms of cognition on which our quest for knowledge is based and accordingly the educational process should be organized. At the same time, he refutes Plato's thesis that these ideas or forms of cognition exist in a supersensible world, because of which they cannot be either proved or described. According to Hirst, these ideas exist rather in our language: they can be described linguistically with concepts, thoughts, logical grammar by those who refer to them, use them. Hirst identifies seven forms of cognition: empirical, mathematical, philosophical, moral, aesthetic and historical-sociological ones. Each of them is unique: it has its own system of concepts, logically unrelated to the system of concepts of the other form of cognition; has its own criterion of truth, with which its concepts are tested; has a specific way of proving the truth, involving both skill and knowledge. Therefore, each form of cognition must be examined by those who practically deal with the issues in question. 
However, the theses formulated by Hirst do not define what is the basis of his proposed distribution of ideas or forms of knowledge. Why, for instance, do such fields of knowledge as medicine, geography, etc. fall out of his classification? Hirst, however, argues that the rest of all branches of knowledge can be reduced to the seven above-listed forms. For example, the empirical form includes the branch of medicine that covers anatomy, physiology and other functions of the human body, the mathematical form includes questions related to blood pressure and biochemical reactions, and the moral form includes thoughts that relate to medical ethics. Regarding the seven basic forms of knowledge listed, because of their uniqueness, none of them can be reduced to other forms.

Hirst strives to overcome the confusion that Plato assumes regarding his division of knowledge into introductory, or informative, and predictive, which Hirst believes opens the way to intuitionism. In his view, however, any form of knowledge is capable of generalizing countless evidential presuppositions, and thus the process of cognition is infinite. Another solution different from Plato's, Hirst offers on the question of the objective nature of ideas, or forms of cognition, and the basis of their objectivity. On the one hand, Hirst denies Plato's understanding of the objectivity of cognition forms as those that exist in the supersensible world and are related to its objective order. On the other hand, he also does not accept the vulgar-naturalistic approach to the interpretation of cognition, according to which forms of cognition are directly determined by the organization of our brain cells. Hirst sees the objectivity of cognition in the fact that due to the linguistic form of knowledge manifestation they become understandable not only to one person, but also to other people. In his work "Knowledge and the Curriculum" he writes: "People can perform all forms of personal experience which are recognizable by them, understandable only to them and in this sense are subjective" [5]. However, when people, having recognized certain forms of experience, describe them by giving them an appropriate symbolic or particularly linguistic expression, these forms of experience acquire the character of objective, accessible to common understanding, analysis and development. "The knowledge expressed by means of a linguistic form becomes objective because this form adds common meaning to concepts. As a result, people become capable of understanding not only the state of their thoughts but also the opinions of others, adopting the same conceptual scheme, learning to use the symbols in the same way as others do" [5].

Hirst's subjective understanding of the source of knowledge is found in the fact that cognition and related experience acquire their meaning through the human ability to see, feel that non-linguistic form of reality, which they reflect. According to Hirst, if not only one person, but others understand the symbols of the phenomena in the same way, then the meaning of these symbols becomes objective. To put it differently, words and symbols create the objective essence of things. Hirst explains his point of view by citing a number of examples. Two people may be in a certain (say, kinship) relationship with each other without having any idea of the nature of that relationship that binds them together. But it is enough to use the word 'cousins' in relation to them, and the nature of this relationship becomes clear and objective not only for these two people, but for everyone else as well. The important thing, as Hirst points out, is that people agree on a certain use of certain concepts in order to give them an objective character. Hirst also illustrates this view with the example of the sense of color. The concept of green, red and other colors becomes objective if people have agreed to objectify by means of language their experience, their perceptions of these colors. Thus, the basis of any classification of phenomena is the internal linguistic communication between people, their consent, but not a reality that takes place outside the language. 
The English philosopher A. Brent also believes that some "fundamental concepts, procedures, classifications and differentiation are determined by human agreement expressed through language. This agreement provides the basis for our reasoning" [6] Objectivity, therefore, emerges in human experience when people "agree" to describe, to express their subjective experience in terms accessible to others. Here Hirst and Brent's position converges with that of J. Dewey. Since, according to Hirst, the implied meaning and objectivity are conceptually related (thoughts can be either true or false, but they cannot be both at the same time), it is understandable that people not only need to express thoughts, beliefs, but also to organize that knowledge, which is general in nature. The seven forms of cognition described by Hirst qualify as such an organization of knowledge.

Therefore, the classification of forms of cognition, according to Hirst, is based on the consent of people, which emerges in the process of their direct communication at that stage of human development, when there were no linguistic and symbolic forms of language expression yet. Later, as a result of conversations, dialogues among scientists, moralists and theologians, various forms of cognition developed. Thus, cognition is reduced to the choice of language, to the "language game". The thoughts to which Hirst reduces knowledge can be verified if the speech in which it is expressed is intelligible. Thus, speech, its structure, its conceptual composition become a criterion of what can be cognized, what can be a bearer of knowledge and what can be a fantasy. In short, speech acts as a source of knowledge. In turn, language can be understood if it symbolizes concepts that are common to people in an accessible form. Therefore, knowledge is first defined in the concept of meaning and only then in the concept of truth. Consequently, it is devoid of an objective source. Hence, the main task of the cognitive process turns out to be the study of language rather than of the objective world, which exists before thinking.

Hirst sees the difference between the forms of cognition in the system of concepts inherent in each of these forms. There are two kinds of concepts: general categories, which define the criterion of the truth of thoughts in a given form of cognition, and substantive concepts, which describe specific phenomena. In morality, the general categories are "good", "right", "proper", while the substantive concepts include "theft", "pride", "humiliation" and other moral concepts, with the help of which the concept of moral duty is derived. Without this last generalizing concept, one cannot determine the specific duties of a person. But what is the nature of moral concepts?

Based on linguistic philosophy and ethics, the creators of the philosophical concept of education and upbringing, which is based on the principle of "new humanism", reduce morality mainly to opinions, in a particular form of their expression. "The term "morality", writes L. Kohlberg, "refers to moral judgments or decisions that are based on opinions, not to behavior, its consequences or effects. Morality is not a rule of conduct. The main thing that gives a rule a moral character is the individual's commitment to it" [7]. In morality, he argues, form is important; morality is a "language game" in which we use the concepts of "right", "good", "duty", "justice" to indicate certain behavior to people. Thus, it is not moral principles themselves that regulate human behavior by virtue of the fact that they have objective content, but rather the arrangement of concepts chosen arbitrarily by us only under the influence of our feelings.

Although the naturalistic approach, as Hirst notes, contributes to the debunking of the religious view of morality by raising the question of its natural basis, the very idea of naturalism, in the 'nature of man' inherent in him/her from birth, should be sought as the key to understanding the rightness of his/her actions, is illusory. It is one thing to establish the cause of human behavior, but another thing - to determine the nature of that behavior, to evaluate it. The latter is not a matter of science, but of morality. Therefore, as Hirst concludes, "it is not morality that should be deduced from 'human nature', but rather on the 
contrary, society needs morality to know what kind of personality should be molded" [8]. Human needs and desires are varied, some of them are of irrational character. Therefore, one cannot look for the rational premise of morality in "human nature" itself.

P. Hirst also rejects the intuitionist and positivist conception of morality, which leaves no room for reason and objectivity to determine the nature of moral judgements, principles and qualities. Thus, he considers the common shortcoming of all existing conceptions of morality to be the lack of an objective approach to it, the consequence of which has been a tendency towards pluralism in moral judgements, which in turn leads to relativism, to the conclusion that any thoughts are good because they are the consequence of our choices. Relativism also interferes with moral life because the possibilities of moral choice are limited in particular circumstances and one needs some kind of criterion for making the right choice. After all, in morality, Hirst notes, "we look within ourselves for the grounds for our actions, which by their nature should be general ... A set of principles is accepted by us because they provide grounds for our actions at a certain level of awareness. But if these realizations are not acceptable in another situation, they quickly cease to play a role as the status of morality for us" [5].

But how does Hirst address the issue of the rationality of morality? Whilst sharing much of the attitude of linguistic ethics, he does not agree with the principle of universalism as the rational basis of morality espoused by the English philosopher R. Hare. Indeed, many rules of conduct that are derived from general principles do not work in a particular situation.

In search of general rules which could serve as a guide for individual behavior, Hirst is forced to abandon a number of provisions that he had previously formulated in his theory of cognition. Thus, he rejects the thesis that thoughts and principles are true, rational for everyone if they are true for a certain group of people. He comes to the conclusion that the education and upbringing based on this thesis are primitive, since it does not resort to methods of explanation, evidence, but only imposes on the new generation the views, attitudes that have already been established. The question of the rationality and truthfulness of the education and upbringing system, in this case, is simply dismissed since there are as many groups in society with their own beliefs and stereotypes as there are systems of moral upbringing.

P. Hirst also opposes the idea, advocated in particular by R. Peters, that the basis for the rationality of morality should be seen in self-evident moral principles such as honesty, the need to tell the truth, to be free, to follow one's own interest and respect the interest of another etc. Such an attitude, he notes, justifies the automatism of an individual's actions and deprives his/her decision of concreteness. Hirst's main request is to find the grounds prerequisites for moral principles, for the individual's activity. However, Hirst does not show proper consistency on this point either. His position is subjectivist in a certain sense and he recognizes people's consent as the basis for the truth, objectivity of moral judgements, when no other justification is found. In this case, people's consent arises as a result of social necessity. However, Hirst points out, this does not resolve questions of moral life. The latter requires reasonable grounds. Therefore, a system of ethical education, limited only to thoughts, beliefs, should address their practical consequences, keeping in mind the objective content of moral choices rather than people's subjective inclinations.

It might seem that Hirst is thereby advocating an objective approach to morality. But his further reasoning does not support this impression. We learn that moral judgements, principles are rational if they are expressed by a person with a highly developed intellect, who exercises free, independent choice in all spheres of life. It is true that Hirst stresses the necessity of a directed mind, a person's ability to choose. Because a person is not an automaton that acts on the basis of certain rules, nor is he/she a trained penguin, his/her 
moral action involves freedom, the understanding of the situation. In this case, he/she can act independently and be responsible for his/her actions, even if he/she cannot justify them. Here "we certainly enter the realm of morality, since the individual could, relying on his or her mind, act differently" [5]. The activity of the mind, as Hirst argues, determines the activity of actions, as the knowledge of what is right or wrong is embedded in the mind.

There can hardly be any doubt that moral judgements and decisions are linked to a certain level of development of the human mind, to its understanding of the nature of occurring events [9]. However, the understanding of one's actions does not yet indicate their moral sense. A sound judgement is not yet a guarantee of its correctness. It is important from which moral values a person derives in his/her thoughts and assessments, to what extent these thoughts correspond to actions because one cannot judge the moral life of a person outside of his/her actions.

Hirst's writings provide a valid point that moral convictions are based on certain values, on the concept of what is right and fair, and without these concepts, one cannot evaluate specific actions of people. Therefore, in the process of upbringing and education, it is important to uncover their meaning and provide them with a rational justification. However, the question of what determines the rationality of morality is left without a clear answer. He cannot get out of the vicious circle of thinking that the rationality of moral judgements and principles is related to the rationally thinking autonomous person, and because these thoughts are made on the basis of reason, they are morally justified [8]. The question of the specific actions to be consistent with an individual's moral judgement, however, falls out of his focus.

The elevation of morality to rational judgement, the existence of which is guaranteed by the intellectual development of the individual, defines, according to the proponents of the principle of "new humanism", the main task of education and moral education - the formation of an intellectually developed autonomous personality. "The maximum development of the rational autonomous personality, his/her understanding of what is reasonable under certain conditions, is our main objective" [8], - writes Hirst, expressing the aim of moral education in a highly abstract way. It is more clearly formulated by L. Kohlberg, the head of the cognitive direction. "The fundamental aim of upbringing and education is to develop individuals with a definite structure of cognition and motivation, that is, individuals capable of serving the establishment of a fairer society" [10].

Naturally, the moral development of a person presupposes a certain level of knowledge, understanding of the essence of events. However, it is impossible to put a sign of equality between knowledge and morality. Hegel wrote that education "makes a person smarter, but does not make him/ her better" [11] It is possible to have a high level of knowledge and remain indifferent to the fate of people and nations. Knowledge must be organically combined with good feelings, with emotions, with an unselfish attitude towards people, not only towards neighbors but also towards outsiders. The rationalism and intellectualism of the advocates of the "new humanism", in fact, remove the question of the objective cause of immoral behavior, attributing it to people's lack of knowledge, their lack of education. However, in social reality, moral behavior is inconceivable without a combination of knowledge, human culture and ethical motives for activity.

Analyzing the structure of morality, almost all proponents of the 'new humanism' agree that it also includes certain virtues, that is, moral qualities that motivate the individual to act in accordance with learned moral norms. These virtues serve as motives for action and are linked to emotions. Some scholars, such as A. Harris, even champion the leading role of emotions in the structure of morality, believing that after emotions, one can judge a person's moral beliefs or ethical stance. "The presence of emotional reactions", Hirst also supports this view, "is a very effective indicator of the existence of an individual's certain beliefs or 
attitudes" [8]. Emotions are the main stimulus for people's actions, an expression of their own response to a particular problem. However, moral emotions, according to Harris, need to be nurtured, and the nature of nurturing them can be different. They can be instilled through training (such a way of nurturing emotions suggested by supporters of various "behavior modification" options), but then they have little to do with morality, which is meant to nurture the rationality of emotions. "Education has to do with the rationality of emotion and the rationality of the actions that result from it" [4]. Harris, therefore, believes that the caregiver in particular and the educator in general must first find a specific criterion for determining the rationality of their own emotions.

Thus, in a broader interpretation, the main purpose of moral education, pedagogy in general and social coordination (social management) is to develop the capacity for moral reasoning, for understanding both 1) one's own feelings and interests and 2) the feelings and interests of others. Harris is convinced that this is the way, and the only way, to develop mature, "autonomous people who are able to express their judgements, supported by some information" [4]. He sees in the rationality of both judgements and emotions the key to making the right choices between different beliefs and thoughts.

Indeed, experiencing events is an important aspect of morality. It is no coincidence that many representatives of contemporary Western social thought fear the decline of the capacity to feel - as a symptom of moral crisis, evidence of the emptiness of a person's inner world. One of the characters in Ch. Snow's novel "A Coat of Varnish", a professor of psychology, says: "It is impossible to enter someone's critical situation ... We all have an insufficient capacity for feeling. It is possible that it is gradually being lost altogether. Sometimes this scares me. I'd rather have bad feelings than no feelings at all. I'd rather have cruelty with no feelings than cruelty without feelings at all. As the evidence shows, the most horrible things happen in the latter case" [12]. Deprived of emotion, morality adopts a rhetorical, common-sense form. However, this does not mean that prudence is the sister of immorality. One cannot agree with Harris that a person's morality can be judged on the basis of emotion. The absolutization of sentiment leads to irrationalism in morality, to the justification of both primitive egoistic aspirations and thoughtless adherence to authority.

Certainly, both a person's emotions and his/her judgement to a certain extent allow to judge his/her morality, to imagine his/her behavior. But the most important, one might say, determining factor that reveals the essence of a person's behavior is his or her specific actions. The more questionable thing is that the rationality of a free person's thoughts and emotions automatically determines the correctness of his or her actions. That is why some foreign authors correct the general course of reasoning of the proponents of this concept. For instance, R. Peters writes: "Upbringing and education mean not only giving knowledge, but also changing and regulating attitudes, emotions, desires and actions of people". He concludes that "education teaches a person how to live" [13]. But neither does Peters provide a definition of the objective factors that ultimately ensure the realization of people's moral beliefs, goals, motives.

Among the advocates of the "new humanism" there are philosophers who aspire to a broader view on the processes of education, learning and upbringing, not confining themselves solely to the development of the methodology of education and upbringing, the capacity and desire to reflect on the problems of morality. This is, in particular, the position of M. Warnock, who does not share the prevailing view in Western moral philosophy and transferred to the philosophy of education and upbringing, stating that morality is only a field of judgement, in the process of reasoning on moral topics people learn moral choices. "We want our children to be intelligent, of course. But we also want them to be truthful, understanding, noble and benevolent in other respects" [14]. While not denying the 
importance of the role of judgement and language in morality, Warnock notes that in the provisions of Hirst and other theorists of this problem one sees an excessive preoccupation with the methodology of the education and upbringing process, its detachment from behavior. Turning to the theory of cognition put forward by Hirst as the ascendant theoretical and methodological guide to the entire education system, in particular the construction of the curriculum, Warnock notes that there is no such thing as "pure forms of cognition".

The attitudes of Hirst and his associates, in her view, do not aim at the object of cognition, but at what lies behind it, while this object itself, i.e., reality, is left out of focus. Certainly, when studying history, for example, one must understand, study the historical method, however, not in its pure form, but in combination with concrete historical events. Focusing on metaproblems, on how one form of cognition differs from another, Hirst misses the substantive side of the issue. With respect to morality this means that we should only be interested in the logic of moral considerations and not in the concrete requirements of morality, the actions themselves, which undoubtedly dilutes moral education by distorting its essence and aims in one way or another. As for the tasks of education and moral upbringing, M. Warnock emphasizes that they should have the future of a person in mind, i.e., help him/her to live a decent life, and for this we should educate him/her in appropriate moral qualities and feelings. "Education should prepare people for a good life, in which they will be able to fulfil a certain role, to perform useful deeds" [14]. A good life is first and foremost a virtuous life. Helping to affirm it and spread it is the most important goal of moral education. Choice in the field of morality, as she correctly observes, is not just a choice of decisions, of attitudes. It is above all a choice of actions, of behavior, requires certain moral qualities, or virtues of the person.

Acknowledging the need for people to develop a certain value orientation, proponents of the "new humanism" pose the question of the role of moral principles in realizing this goal of moral education. However, there is no unanimity in their interpretation of this issue. R. Peters, for example, believes that moral education is education in the spirit of simple moral norms, adapted in its concrete content to the life of the education system and school [13].

Objecting to such a simplistic interpretation of moral education, M. Warnock and P. Hirst rightly point out that simple moral standards in relation to the life and work of the school do not extend beyond its regulations, the requirements of which are largely devoid of a moral aspect (they may, for example, relate to dress code, etiquette, etc.), they are difficult to justify rationally, but one can only demand that students obey them unconditionally. Finally, M. Warnock sees the main goal of moral education in teaching young people to understand the difference between moral behavior (which need not be against the norms) and non-conforming behavior. At the same time, she offers no criteria for defining immoral behavior and does not make it clear how to evaluate behavior that does not conform to norms. This requires a clear idea of which norms are in question, and Warnock's position remains ambiguous. However, none of the aforementioned theorists indicate under what conditions an individual freely follows moral requirements, what sense of moral principles motivates people to voluntarily accept them as a guide for their actions. Neither Warnock nor her colleagues link this to the underlying interests and needs of the individual. Moral principles, on the other hand, can only guide actions when they have been understood by the individual and voluntarily accepted by him or her.

In preparing for life, young people must, first of all, understand what proper behavior, actions and intentions are. Schools and institutions of higher education must, therefore, shape a personality with certain inclinations and inclinations, striving to change, smooth out those aspects of the pupils' character that contradict the idea of correct, proper behavior 
Sintschenko «Gesellschaft und Ethik im...»[15]. In the process of upbringing and education, it is necessary to achieve a social sense of duty, responsibility and the ability to think about the interests of others, so that the pupils of the school (that is, the education and upbringing system / educational institutions), when they leave its walls, are able to pursue the right thoughts and decisions that they have taken or have adopted in life. Conscious perception of moral ideas alone is therefore clearly not enough to change the moral atmosphere of society.

Therefore, even C. Silbermann, who considers a high level of education, intellectuality of students to be the main aim of education and upbringing, states that it is necessary to educate a person who is not only able to think, but also to feel and act, and the task is to turn "ideas about morality into moral ideas" [16]. It is essentially a question of shaping a person's moral beliefs, ideals and feelings. An attempt to link morality with behavior is observed in A. Harris's works, who believes that morality is a medium of thoughts about what a person should do, about good and evil, duty, and responsibilities, but he agrees that because moral thoughts are prescriptive, the line of behavior is not chosen by a person consciously, i.e., freely.

However, the advocates of the "new humanism" are aware of the fact that moral thoughts are different in nature. And since moral education must in its essence focus on the moral choices of the individual, the problem arises of determining the rational basis for moral judgements, which is crucial to an understanding of morality itself. Hirst, who opposes the naturalistic approach to the problem, in particular the position that the foundations of morality are embedded in human nature, is more concerned with this problem than others in this branch of educational philosophy. Hirst rightly points out that such an approach virtually eliminates the problem of education. His writings contain the important idea that morality, its foundations, arguments in favor of a particular thought are not innate, but are conditioned by the influence of society. "The individual himself can learn little from the natural environment, it is only through education in society that patterns of arguments (in favor of a certain thought) are transmitted from generation to generation and gradually develop into his/her own form of reasoning. Likewise, the tendency to exhibit feelings of guilt has a natural basis. But what gives rise to such a feeling, namely, a pattern of conscience, is not an innate call of morality. It is a consequence of social development" $[8]$.

Whereas the transmission of knowledge relates to the human intellect, the formation of a certain value orientation (education and upbringing in the proper sense of these terms) is linked to human action, contributing to the transformation of certain value orientations into a person's beliefs [17].

\section{Conclusions}

The reduction of educational philosophy and educational management to purely moral philosophy is not justified, at least because the subject matter of the latter includes a number of issues that should be dealt with by the philosophy of education and upbringing. Moral philosophy, ethics deal with a broader object of study - morality, which permeates all the segments of social and individual life. Therefore, the position of those researchers who attribute ethics a central place in the philosophy of education and upbringing, rather than identifying their problems, seems more convincing. At the same time, their model of the philosophy of education and upbringing remains rather abstract as well, since they do not define, specify, clearly delineate the functions of ethics in the system of the philosophy of education and upbringing. However, the problems of philosophical justification of the education/social upbringing process cannot be solved without this. The very idea of "new 
humanism" of the need for an integral, comprehensive approach to the problems of education and upbringing from the perspective of a philosophical understanding of all the most important aspects of the education and upbringing process and social management deserves attention.

Given the growing need for the practical realization of the ideas of freedom, justice and human rights, the advocates of the "new humanism" see their main objective as preventing conformism, the manipulation of individual behavior and creating conditions for free selfexpression, for the exercise of a thorough choice of actions in a given situation and thus preventing the danger of a unified form of behavior.

\section{References}

1. T. Bufford, Toward a Philosophy Education (World-Press, Boston, 2016)

2. A. Harris, Teaching, Morality and Religion (Allen and Unwin, London, 2006)

3. R. Barrow, Moral Philosophy for Education (George Allen and Unwin, Boston, London, 2008)

4. A. Harris, Teaching, Morality and Religion. (Routledge, London, 2020)

5. P. H. Hirst, Knowledge and the Curriculum. Knowledge and the Curriculum: A Collection of Philosophical Papers (Routledge \& Kegan Paul Books, London, n.d.)

6. A. Brent, Philosophical Foundations for the Curriculum (Allen \& Unwin, London, 2017)

7. L. Kohlberg, Stages of Moral Development as a Basis for Moral Education. (University Press, Bangor, 2012)

8. P. H. Hirst, Moral Education in a Secular Society (University of London Press, London, 2014)

9. V. V. Zinchenko, Communication Discourse: Personality, Society, Practice (PGU, 2014)

10. L. Kohlberg, Education for a Just Society. (Moral Development, Moral Education. Ethics and Educational Policy). (Munsey, Birmingham, 2016)

11. G. W. F. Hegel, Works of Different Years (M Think, 1970)

12. C. Snow, New World (Lakovka, 1981)

13. R. Peters, Education and Values (Sloan, New York, 2019)

14. M. Warnoc, Schools of Thought (Faber, London, 2017)

15. V. V. Sintschenko, Suhrkamp Publ. Sozialforsch. 3, 54 (2016)

16. C. Silberman, Crisis in the Classroom; the Remaking of American Education (Random House, New York, 2015)

17. V. V. Zinchenko, V. V. Levkulych, V. V. Levkulych, and V. Y. Svyshcho, IOP Conf. Ser. Earth Environ. Sci. 635, (2021) 